Article

\title{
Why Did All Patients with Atrial Fibrillation and High Risk of Stroke Not Receive Oral Anticoagulants? Results of the Polish Atrial Fibrillation (POL-AF) Registry
}

\author{
Anna Szpotowicz ${ }^{1}$, Iwona Gorczyca ${ }^{2,3, *}{ }^{\mathbb{D}}$, Olga Jelonek ${ }^{2,3}{ }^{(\mathbb{D}}$, Beata Uziębło-Życzkowska ${ }^{4}{ }^{\mathbb{C}}$, \\ Małgorzata Maciorowska ${ }^{4}{ }^{\oplus}$, Maciej Wójcik ${ }^{5} \mathbb{D}^{-}$, Robert Błaszczyk $^{5}{ }^{\circledR}$, Agnieszka Kapłon-Cieślicka ${ }^{6}$, \\ Monika Gawałko ${ }^{6,7,8}{ }^{(D}$, Monika Budnik ${ }^{6}$, Tomasz Tokarek ${ }^{9}{ }^{(D}$, Renata Rajtar-Salwa ${ }^{9}$, Jacek Bil ${ }^{10}{ }^{(D)}$, \\ Michał Wojewódzki ${ }^{10}$, Janusz Bednarski ${ }^{11,12}$, Elwira Bakuła-Ostalska ${ }^{11}$, Anna Tomaszuk-Kazberuk ${ }^{13}$ (D), \\ Anna Szyszkowska ${ }^{13}$, Marcin Wełnicki ${ }^{14}{ }^{\mathbb{D}}$, Artur Mamcarz ${ }^{14} \mathbb{D}$, Małgorzata Krzciuk ${ }^{1}$ \\ and Beata Wożakowska-Kapłon 2,3
}

1 Department of Cardiology, Regional Hospital, 27-400 Ostrowiec Swietokrzyski, Poland; szpotowiczanna@wp.pl (A.S.); mekrzciuk@gmail.com (M.K.)

2 1st Clinic of Cardiology and Electrotherapy, Swietokrzyskie Cardiology Centre, 25-736 Kielce, Poland; olga_jelonek@wp.pl (O.J.); bw.kaplon@poczta.onet.pl (B.W.-K.)

3 Collegium Medicum, The Jan Kochanowski University, 25-369 Kielce, Poland

check for updates

Citation: Szpotowicz, A.;

Gorczyca, I.; Jelonek, O.;

Uziębło-Życzkowska, B.; Maciorowska, M.; Wójcik, M.; Błaszczyk, R.; Kapłon-Cieślicka, A.; Gawałko, M.; Budnik, M.; et al. Why Did All Patients with Atrial Fibrillation and High Risk of Stroke Not Receive Oral Anticoagulants? Results of the Polish Atrial Fibrillation (POL-AF) Registry. J. Clin. Med. 2021, 10, 4611. https://doi.org/10.3390/jcm10194611

Academic Editor: Sandro Gelsomino

Received: 3 September 2021

Accepted: 4 October 2021

Published: 8 October 2021

Publisher's Note: MDPI stays neutral with regard to jurisdictional claims in published maps and institutional affiliations.

Copyright: (c) 2021 by the authors. Licensee MDPI, Basel, Switzerland. This article is an open access article distributed under the terms and conditions of the Creative Commons Attribution (CC BY) license (https:/ / creativecommons.org/licenses/by/ $4.0 /)$.
4 Department of Cardiology and Internal Diseases, Military Institute of Medicine, 04-141 Warsaw, Poland; buzieblo-zyczkowska@wim.mil.pl (B.U.-Ż.); mmaciorowska@wim.mil.pl (M.M.)

5 Department of Cardiology, Medical University of Lublin, 20-059 Lublin, Poland; m.wojcik@umlub.pl (M.W.); robertblaszczyk1@wp.pl (R.B.)

6 1st Chair and Department of Cardiology, Medical University of Warsaw, 02-097 Warsaw, Poland; agnieszka.kaplon@gmail.com (A.K.-C.); mongawalko@gmail.com (M.G.); moni.budnik@gmail.com (M.B.)

7 West German Heart and Vascular Centre, Institute of Pharmacology, University Duisburg-Essen, 45141 Essen, Germany

8 Department of Cardiology, Cardiovascular Research Institute Maastricht, Maastricht University Medical Centre, 6211LK Maastricht, The Netherlands

9 Department of Cardiology and Cardiovascular Interventions, University Hospital, 30-688 Krakow, Poland; tomek.tokarek@gmail.com (T.T.); rajfura@op.pl (R.R.-S.)

10 Centre of Postgraduate Medical Education, Department of Invasive Cardiology, Central Clinical Hospital of the Ministry of Interior and Administration, 02-507 Warsaw, Poland; biljacek@gmail.com (J.B.); michaljerzywojewodzki@gmail.com (M.W.)

11 Department of Cardiology, St John Paul II Western Hospital, Clinic of Cardiology, 05-825 Grodzisk Mazowiecki, Poland; medbed@wp.pl (J.B.); elwira.bakula@gmail.com (E.B.-O.)

12 Medical Department, Lazarski University, 02-662 Warsaw, Poland

13 Department of Cardiology, Medical University, 15-276 Bialystok, Poland; a.tomaszuk@poczta.fm (A.T.-K.); annaszyszkowska92@gmail.com (A.S.)

14 3rd Department of Internal Diseases and Cardiology, Warsaw Medical University, 02-097 Warsaw, Poland; welnicki.marcin@gmail.com (M.W.); artur.mamcarz@wum.edu.pl (A.M.)

* Correspondence: iwona.gorczyca@interia.pl; Tel.: +48-604-407-956

Abstract: Background: Most atrial fibrillation (AF) patients are at high risk of thromboembolic, and the use of oral anticoagulants (OACs) is advised in such cases. The aim of the study was to evaluate the frequency at which OACs were used in patients with AF and high risk thromboembolic complications, and identify factors that result in OACs not being used in the researched group of patients. Methods: The prospective, multicenter and non-interventional POL-AF registry is a study that includes AF patients from ten Polish cardiology centers. They were consecutively hospitalized between January and December of 2019. All the patients in the study were of high stroke risk. Results: A total of 3614 patients with AF and high stroke risk were included. Among the total study population, $91.5 \%$ received OAC therapy; antiplatelet therapy was prescribed for $3.7 \%$ of patients, heparin for $2.7 \%$, and $2.1 \%$ of patients did not receive any stroke prevention therapy. Independent predictors of no OAC prescription were intracranial bleeding (OR 0.15, 95\%CI 0.07-0.35, $p<0.001$ ), gastrointestinal bleeding (OR 0.25, 95\%CI 0.17-0.37, $p<0.001$ ), cancer (OR 0.37, 95\%CI 0.25-0.55, $p<0.001$ ), hospitalization due to acute coronary syndrome (OR $0.48,95 \%$ CI $0.33-0.69, p<0.001$ ), and anemia (OR 0.62, 95\%CI 0.48-0.81, $p<0.001$ ). Conclusions: Most AF patients with a high 
thromboembolic risk received OACs. The factors predisposing a lack of OAC use in these patients were conditions that significantly increased the risk of bleeding complications.

Keywords: atrial fibrillation; non-vitamin $\mathrm{K}$ antagonist oral anticoagulants; oral anticoagulants; stroke risk; vitamin $\mathrm{K}$ antagonists

\section{Introduction}

Thromboembolic complications are the most serious implications of atrial fibrillation (AF) [1,2]. The danger of thromboembolic complications in patients with AF is not homogeneous and depends on age, sex, and concomitant diseases [3,4]. To evaluate the risk of thromboembolic complications, scores including risk factors of thromboembolic complications should be used [5]. The score recommended to evaluate the thromboembolic risk in patients with $\mathrm{AF}$ is the $\mathrm{CHA}_{2} \mathrm{DS}_{2}$-VASc score. The group of patients with high risk of thromboembolic complications comprises men who receive at least 2 points and women with at least 3 points in the $\mathrm{CHA}_{2} \mathrm{DS}_{2}$-VASc score [6]. Most patients with AF are at high risk of thromboembolic complications $[7,8]$. According to the current guidelines of the European Society of Cardiology (ESC), AF patients with a high risk of thromboembolic complications should receive anticoagulant treatment [9]. However, not all patients receive this treatment.

The aim of this study was to evaluate the frequency of oral anticoagulant (OAC) use in $\mathrm{AF}$ patients with a high risk of thromboembolic complications and to identify factors predisposing against the use of OACs in the researched group of patients.

\section{Methods and Materials}

\subsection{Study Population}

The presented study was written on the basis of the Polish, multicenter, prospective Polish Atrial Fibrillation Registry (POL-AF) comprising 10 cardiology hospitals (ClinicalTrials.gov: NCT04419012). The recruitment period lasted from 1 January 2019 to 1 December 2019, and subsequently hospitalized patients diagnosed with AF joined the study. The study's inclusion criteria were: diagnosed AF and age $\geq 18$ years. Patients who died during hospitalization and those with valvular AF (valve prosthesis, at least moderate mitral stenosis) were excluded from the study. Additionally, patients hospitalized in order to have AF substrate ablation were not included. The data concerning comorbidities, laboratory research results, and anticoagulant treatments were evaluated.

Patients with a high risk of thromboembolic complications were included in the presented study. In total, after adopting the aforementioned exclusion criteria, 3614 patients were included (Figure 1).

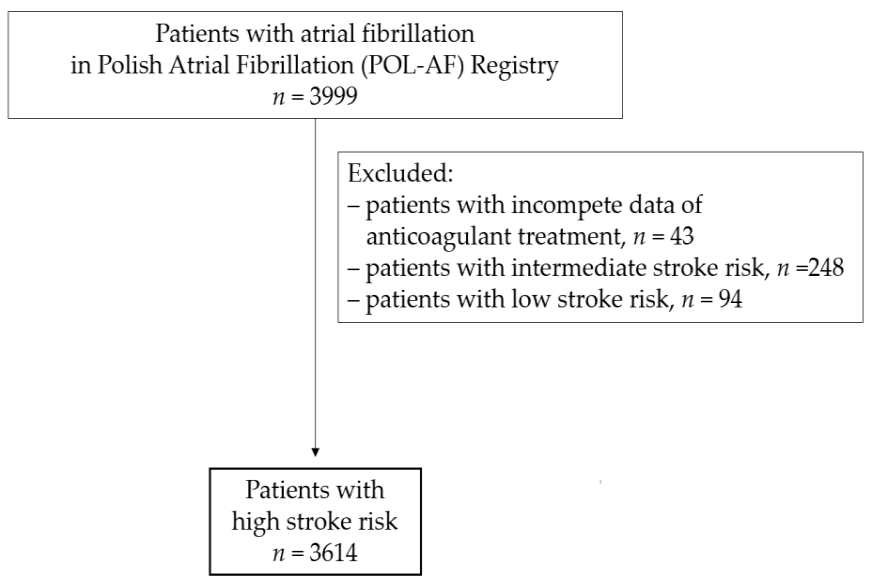

Figure 1. Study flow chart. 


\subsection{Covariates}

Researchers collected data regarding medical records, demographics, diagnostic test results, AF type, and pharmacotherapy.

The HAS-BLED (Hypertension, Abnormal Renal/Liver Function, Stroke, Bleeding, Labile INR, Elderly ( $>65$ years), Drug/Alcohol Consumption) score was used to assess bleeding risk [10].

The CKD-EPI equation was applied to calculate the estimated glomerular filtration rate (eGFR), which was used to evaluate the function of patients' kidneys.

The Ethics Committee of the Świętokrzyska Medical Chamber in Kielce (104/2018) approved the study. It also waived the requirement of obtaining informed consent from the patients.

\subsection{Stroke Risk Assessment}

Thromboembolic risk was defined according to the $\mathrm{CHA}_{2} \mathrm{DS}_{2}$-VASc (Congestive Heart Failure, Hypertension, Age $\geq 75$ years, Diabetes Mellitus, Stroke/Transient Ischemic Attack, Vascular Disease, Age 65-74 Years, Sex Category) score [11-14].

Stroke risk was assessed using the $\mathrm{CHA}_{2} \mathrm{DS}_{2}$-VASc score and was categorized as low (score 0 for males, 1 for females), intermediate (score 1 for males and 2 for females) and high risk (score $\geq 2$ for males and $\geq 3$ for females). Patients with a high thromboembolic complication risk according to their $\mathrm{CHA}_{2} \mathrm{DS}_{2}$-VASc score were included in the study.

\subsection{Stroke Prevention Assessment}

An evaluation of antithrombotic therapy advised during patients' hospital discharge was made. It was possible to define the following four types of regimen: no antithrombotic treatment, $\mathrm{OAC} \pm$ antiplatelet drug (APT), APT only, and heparin. The OAC group included vitamin K antagonist (VKA), apixaban, rivaroxaban, and dabigatran. Despite being registered in Europe as a pharmaceutical against thromboembolic complications in AF patients, edoxaban was not obtainable in Poland. The APT group included ticagrelor, acetylsalicylic acid and/or clopidogrel, and prasugrel.

\subsection{Statistical Analyses}

Statistical analysis was conducted with the use of the STATISTICA 13.3 statistical package. Quantitative variables were presented as mean values with the standard deviations, whereas qualitative data were presented as numbers and percentages.

Next, multivariate logistic regression was performed to calculate multivariate odds ratios together with $95 \%$ confidence intervals. For that purpose, continuous variables such as age, hemoglobin level, and estimated glomerular filtration rate were changed into categorical variables. In the analysis, $p<0.05$ was considered statistically significant.

\section{Results}

\subsection{Baseline Characteristics}

Among the 3614 patients included in the analysis, the mean age of the total population was $73.6 \pm 10.3$ years, where $43.5 \%$ were female. Hypertension was the most common comorbidity $(87.4 \%)$, and $70 \%$ of the patients had a heart failure. Among non-cardiac comorbidities, impaired renal function was the most common diagnosis $(47.9 \%)$. The most commonly reported AF type was paroxysmal AF (47.7\%), whereas $30.1 \%$ of patients had a permanent AF.

In the present study, all patients had a high stroke risk, and $52.8 \%$ of the patients had a $\mathrm{CHA}_{2} \mathrm{DS}_{2}$-VASc score $\geq 5$ points. High bleeding risk according to the HAS-BLED score was diagnosed in $33.4 \%$ of the patients.

The patients from the study group were most often admitted to hospitals in need of electrical cardioversion (22\%) and due to worsening of heart failure (21.8\%).

Baseline characteristics of patients according to antithrombotic strategies are presented in Table 1. 
Table 1. Baseline characteristics of the study group according to antithrombotic strategies.

\begin{tabular}{|c|c|c|c|c|c|}
\hline \multirow[b]{2}{*}{ Clinical Characteristic } & \multirow[b]{2}{*}{$\begin{array}{c}\text { All } \\
n=3614\end{array}$} & \multirow[b]{2}{*}{$\underset{n=3306}{\text { OAC }}$} & \multicolumn{3}{|c|}{$\begin{array}{c}\text { No OAC } \\
n=308\end{array}$} \\
\hline & & & $\begin{array}{c}\mathrm{APT} \\
n=135\end{array}$ & $\begin{array}{l}\text { Heparin } \\
n=96\end{array}$ & $\begin{array}{c}\text { Without } \\
\text { any Stroke } \\
\text { Prophylaxis } \\
n=77\end{array}$ \\
\hline $\begin{array}{c}\text { Age } \\
\text { mean (SD), years }\end{array}$ & $73.6(10.3)$ & $73.5(10.2)$ & $74.6(10.3)$ & $72.6(10.2)$ & $77.1(12.1)$ \\
\hline$<65$ & $598(16.5)$ & $555(16.8)$ & $18(13.3)$ & $15(15.9)$ & $10(13.3)$ \\
\hline $65-74$ & 1285 (35.6) & $1188(35.9)$ & $46(34.1)$ & $39(40.6)$ & $24(31.2)$ \\
\hline$\geq 75$ & $1731(47.9)$ & $1563(47.3)$ & $71(52.6)$ & $42(43.8)$ & $43(55.8)$ \\
\hline Female & $1572(43.5)$ & $1445(43.7)$ & $60(44.4)$ & $48(50.0)$ & $32(41.6)$ \\
\hline \multicolumn{6}{|c|}{ Type of atrial fibrillation } \\
\hline Paroxysmal & $1723(47.7)$ & $1569(47.5)$ & $80(59.3)$ & $57(59.4)$ & $35(45.5)$ \\
\hline Persistent & $803(22.2)$ & $760(23.0)$ & $14(10.4)$ & 15 (15.6) & 15 (19.5) \\
\hline Permanent & $1088(30.1)$ & 977 (29.6) & $41(30.4)$ & $24(25.0)$ & $27(35.1)$ \\
\hline \multicolumn{6}{|c|}{ Medical history } \\
\hline Hypertension & $3174(87.4)$ & $2918(88.3)$ & $112(83.0)$ & $83(86.5)$ & $63(81.8)$ \\
\hline Heart failure & $2529(70.0)$ & $2311(69.9)$ & $92(68.1)$ & $60(62.5)$ & $50(64.9)$ \\
\hline Vascular disease & $2207(61.1)$ & 2005 (60.6) & $112(83.0)$ & $64(66.7)$ & $42(54.5)$ \\
\hline Coronary artery disease & $1979(54.8)$ & $1796(54.3)$ & $107(79.3)$ & $59(61.5)$ & $36(46.8)$ \\
\hline Previous myocardial infarction & $881(24.4)$ & $782(23.7)$ & $60(44.4)$ & $25(26.0)$ & $18(23.4)$ \\
\hline Peripheral artery disease & $564(15.6)$ & $500(15.1)$ & $32(23.7)$ & $21(21.9)$ & $11(14.3)$ \\
\hline $\begin{array}{c}\text { Previous stroke/TIA/systemic } \\
\text { embolism }\end{array}$ & $648(17.9)$ & $599(18.1)$ & $25(18.5)$ & $28(29.2)$ & $8(10.4)$ \\
\hline Diabetes mellitus & $1341(37.1)$ & $1218(36.8)$ & $53(39.3)$ & $35(36.5)$ & $32(41.6)$ \\
\hline Any previous bleeding & $118(3.3)$ & $93(2.8)$ & $14(10.4)$ & $3(3.1)$ & $4(5.2)$ \\
\hline Intracranial bleeding & $29(0.8)$ & $18(0.5)$ & $4(3.0)$ & $0(0.0)$ & $2(2.6)$ \\
\hline Gastrointestinal bleeding & $149(4.1)$ & $138(4.2)$ & $4(3.0)$ & $2(2.1)$ & $4(5.2)$ \\
\hline Cancer & $186(5.1)$ & $149(4.5)$ & $13(9.6)$ & $8(8.3)$ & $5(6.5)$ \\
\hline Hemoglobin $<12 \mathrm{~g} / \mathrm{dL}$ & $872(24.1)$ & $751(22.7)$ & $45(33.3)$ & $25(26.0)$ & $30(39.0)$ \\
\hline $\mathrm{eGFR}<60 \mathrm{~mL} / \mathrm{min} / 1.73 \mathrm{~m}^{2}$ & $1731(47.9)$ & $1555(47.0)$ & $80(59.3)$ & $40(41.7)$ & $40(51.9)$ \\
\hline $\mathrm{eGFR}<30 \mathrm{~mL} / \mathrm{min} / 1.73 \mathrm{~m}^{2}$ & $255(6.2)$ & $178(5.4)$ & $24(17.8)$ & $11(11.5)$ & $12(15.6)$ \\
\hline \multicolumn{6}{|c|}{ Thromboembolic risk } \\
\hline $\begin{array}{c}\mathrm{CHA}_{2} \mathrm{DS}_{2} \text { VASc score } \\
\text { mean (SD) }\end{array}$ & 4.7 (1.6) & $4.7(1.6)$ & 4.9 (1.6) & 4.9 (1.6) & $4.5(1.4)$ \\
\hline$\geq 3$ & $3331(92.2)$ & $3047(92.2)$ & $128(94.8)$ & $90(92.8)$ & $72(93.5)$ \\
\hline$\geq 5$ & $1909(52.8)$ & $1737(52.5)$ & $80(59.3)$ & $57(59.4)$ & $39(50.6)$ \\
\hline \multicolumn{6}{|c|}{ Bleeding risk } \\
\hline $\begin{array}{l}\text { HAS-BLED score } \\
\text { mean (SD) }\end{array}$ & $2.2(0.8)$ & $2.2(0.8)$ & $2.3(0.9)$ & $2.21(0.9)$ & $2.2(0.8)$ \\
\hline$\geq 3$ & $1208(33.4)$ & $1078(32.6)$ & $58(43.0)$ & $33(34.4)$ & $27(35.1)$ \\
\hline$\geq 5$ & $13(0.4)$ & $11(0.3)$ & $1(0.7)$ & $0(0.0)$ & $0(0.0)$ \\
\hline \multicolumn{6}{|c|}{ Reason for hospitalization } \\
\hline Electrical cardioversion & $796(22.0)$ & $784(23.7)$ & $5(3.7)$ & $21(21.9)$ & $4(5.2)$ \\
\hline Planned coronarography/PCI & $372(10.3)$ & $338(10.2)$ & $21(15.6)$ & $7(7.3)$ & $5(6.5)$ \\
\hline CIED implantation/reimplantation & $346(9.6)$ & $329(10.0)$ & $5(3.7)$ & $11(11.5)$ & $5(6.5)$ \\
\hline Acute coronary syndrome & $240(6.6)$ & $197(6.0)$ & $38(28.1)$ & $7(7.3)$ & $4(5.2)$ \\
\hline Heart failure & $788(21.8)$ & $714(21.6)$ & $24(17.8)$ & $16(16.7)$ & $23(29.9)$ \\
\hline Ablation other than AF & $189(5.2)$ & $172(5.2)$ & $8(5.9)$ & $7(7.3)$ & $7(9.1)$ \\
\hline AF without any procedures & $191(5.3)$ & $180(5.4)$ & $4(3.0)$ & $5(5.2)$ & $3(3.9)$ \\
\hline
\end{tabular}

Abbreviations: AF, atrial fibrillation; APT, antiplatelet drug; CIED, cardiac implantable electronic device; eGFR, estimated glomerular filtration rate; IQR, interquartile range; $\mathrm{OAC}$, oral anticoagulant; $\mathrm{PCI}$, percutaneous coronary intervention; SD, standard deviation; TIA, transient ischemic attack. 


\subsection{Antithrombotic Therapy Use}

In the presented study, 3306 patients $(91.5 \%)$ received OACs, 135 patients $(3.7 \%)$ received APT,96 $(2.7 \%)$ received heparin, and $77(2.1 \%)$ were without OACs or APT.

In the group treated with OACs, 603 patients received VKA, and $2703(82 \%)$ were treated with non-vitamin $\mathrm{K}$ antagonist oral anticoagulants (NOACs). Among NOACtreated patients, $1076(39.8 \%)$ were administered rivaroxaban, $893(33 \%)$ received apixaban, and $734(27.2 \%)$ received dabigatran.

In the study group, 1059 patients (39.2\%) received a reduced NOAC dose. Reduced NOAC was also applied in 321 dabigatran patients (43.7\%), 409 rivaroxaban patients (38\%), and 329 apixaban patients (36.8\%). Appropriate NOAC dose reduction was observed in 769 patients $(72.6 \%)$, and inappropriate NOAC dose reduction was observed in 242 patients (22.9\%). The remaining 48 patients $(4.5 \%)$ lacked data allowing the assessment of the appropriateness of the reduced NOAC dose choice. Figure 2 shows the OAC prescription based on the $\mathrm{CHA}_{2} \mathrm{DS}_{2}-\mathrm{VASc}$ score and Figure 3 shows the prescription of OACs based on the HAS-BLED score.

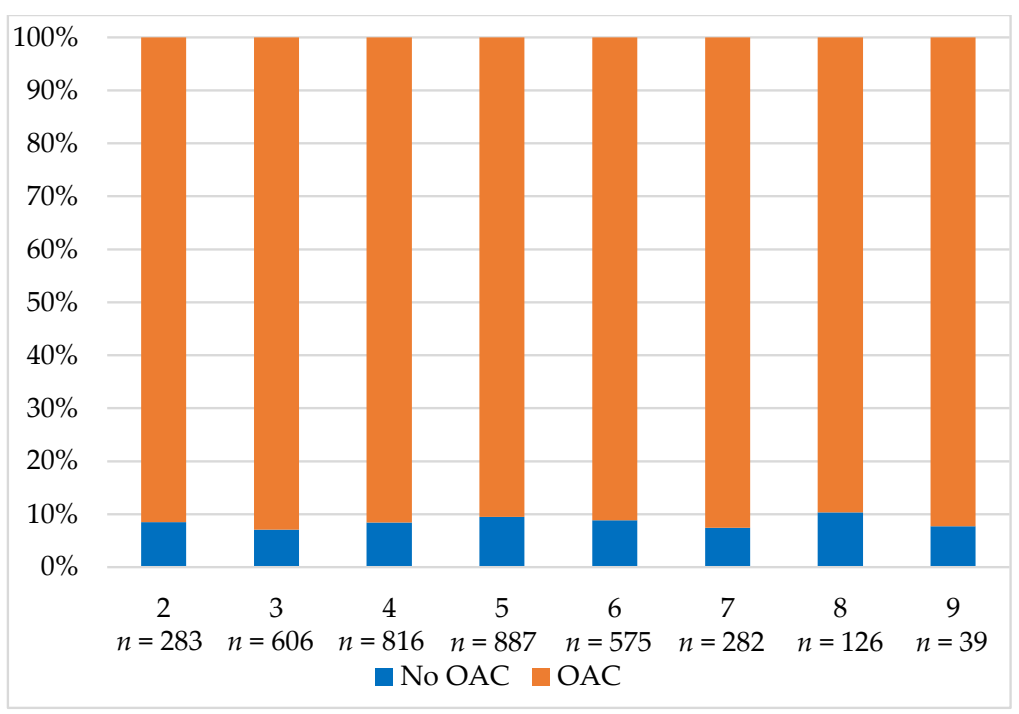

Figure 2. The prescription of $\mathrm{OAC}$ based on the $\mathrm{CHA}_{2} \mathrm{DS}_{2}$-VASc score. Abbreviation: OAC, oral anticoagulant.

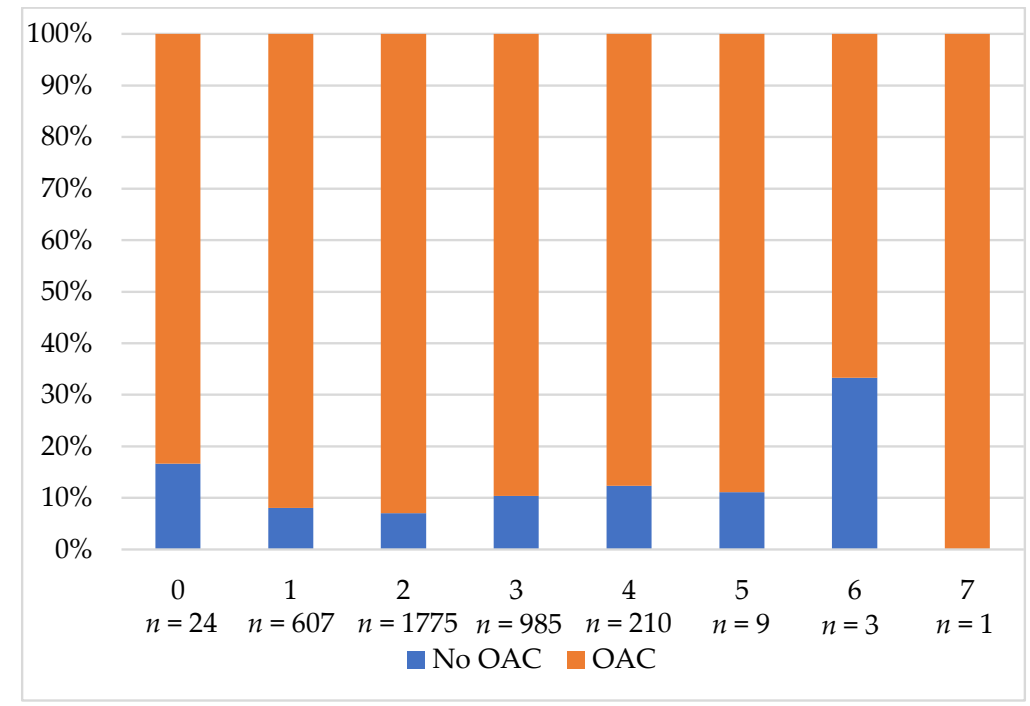

Figure 3. The prescription of OAC based on the HAS-BLED score. Abbreviation: OAC, oral anticoagulant. 


\subsection{Predictors of the Individual Stroke Prevention Use}

During the analysis of individual antithrombotic strategy selections, it was possible to create logistic regression models for OACs versus no OACs.

The univariate logistic regression analysis showed multiple predictors of a specific OAC choice (Table S1). In the multivariable model, factors linked to the prescription of an OAC included the following: age $\geq 75$, hypertension, previous myocardial infarction, peripheral arterial disease, gastrointestinal bleeding, intracranial bleeding, cancer, hospitalization due to electrical cardioversion, hospitalization due to acute coronary syndromes, hemoglobin $<12 \mathrm{~g} / \mathrm{dL}$, and eGFR $<60 \mathrm{~mL} / \mathrm{min} / 1.73 \mathrm{~m}^{2}$.

Table 2 demonstrates predictors of the use of OAC. Independent predictors of the OAC use included hospitalization due to electrical cardioversion (OR 6.02, 95\%CI 3.32$10.89, p<0.001$ ) and hypertension (OR 1.40, 95\%CI 1.01-1.95, $p=0.049$ ). Intracranial bleeding (OR 0.15, 95\%CI 0.07-0.35, $p<0.001$ ), gastrointestinal bleeding (OR $0.25,95 \% \mathrm{CI}$ $0.17-0.37, p<0.001$ ), cancer (OR $0.37,95 \%$ CI $0.25-0.55, p<0.001$ ), hospitalization due to acute coronary syndromes (OR $0.48,95 \%$ CI $0.33-0.69, p<0.01$ ), and hemoglobin $<12 \mathrm{~g} / \mathrm{dL}$ (OR $0.62,95 \%$ CI $0.48-0.81, p<0.01$ ) decreased the likelihood of using OACs.

Table 2. Factors associated with the selection of an OAC over no OAC for stroke prevention in AF patients: multivariable logistic regression models.

\begin{tabular}{cccc}
\hline \multirow{2}{*}{ Factors } & \multicolumn{3}{c}{ OAC Versus No OAC } \\
\cline { 2 - 4 } & OR & $\mathbf{9 5 \% \mathbf { C I }}$ & $p$ \\
\hline $\begin{array}{c}\text { Hospitalization due to electrical } \\
\text { cardioversion }\end{array}$ & 6.02 & $3.32-10.89$ & $<0.001$ \\
\hline Hypertension & 1.40 & $1.01-1.95$ & 0.049 \\
\hline Age $\geq 75$ & 1.06 & $0.82-1.36$ & 0.701 \\
\hline Myocardial infarction & 0.89 & $0.68-1.17$ & 0.400 \\
\hline Peripheral artery disease & 0.88 & $0.64-1.21$ & 0.411 \\
\hline Intracranial bleeding & 0.15 & $0.07-0.35$ & $<0.001$ \\
\hline Gastrointestinal bleeding & 0.25 & $0.17-0.37$ & $<0.001$ \\
\hline Cancer & 0.37 & $0.25-0.55$ & $<0.001$ \\
\hline Hospitalization due to acute & 0.48 & $0.33-0.69$ & $<0.001$ \\
\hline coronary syndrome & 0.62 & $0.48-0.81$ & $<0.001$ \\
\hline Hemoglobin $<12 \mathrm{~g} / \mathrm{dL}$ & 0.86 & $0.67-1.11$ & 0.238 \\
\hline eGFR $<60$ mL/min/1.73 $\mathrm{m}^{2}$ & & & \\
\hline Abbring
\end{tabular}

Abbreviation: $\mathrm{CI}$, confidence interval; eGFR, estimated glomerular filtration rate; OAC, oral anticoagulant; OR, odds ratio.

\section{Discussion}

The present study provides significant insight into antithrombotic therapy in highstroke-risk patients with AF. The main observations are as follows. OAC non-prescription in stroke prevention in high-risk patients with $\mathrm{AF}$ was low. A high percentage of patients administered anticoagulants were treated with NOACs. We identified factors associated with a decreased likelihood of OAC prescription, and all were associated with high bleeding risk.

According to the guidelines of the European Society of Cardiology (ESC) as well as expert documents, it is advisable to use OACs in AF patients with a high risk of thromboembolic complications [9-13]. In some percent of AF patients there are contraindications to the use of OACs, and therefore it will never happen in the real world that all patients with $\mathrm{AF}$ who are recommended OACs will take them. In the present study, OACs were not used in $8.5 \%$ of AF patients with high thromboembolic complication risk. A comparison of our observations to the findings of other established AF registries indicates 
that there are principal regional differences in the prescription of OACs, and that it varies widely depending on the study period and study population. In a Korean population of high-stroke-risk AF patients, $17 \%$ were prescribed no antithrombotic therapy [14]. In the National Cardiovascular Data Registry (NCDR)'s Practice Innovation and Clinical Excellence (PINNACLE) Registry involving 674,841 AF patients of high stroke risk, authors noted that $43 \%$ of patients did not receive OACs, although the proportion of those without OAC treatment varied considerably within clinically relevant strata [15]. Among AF patients with $\mathrm{CHA}_{2} \mathrm{DS}_{2}-\mathrm{VASc} \geq 2,31 \%$ and $13 \%$ of patients in the Global Anticoagulant Registry in the FIELD-Atrial Fibrillation (GARFIED-AF) and Outcomes Registry for Better Informed Treatment of Atrial Fibrillation (ORBIT-AF) II, respectively, were not treated with OACs. Among these patients, there was significant geographic variability in the non-use of OACs across countries, from $69 \%$ to $7 \%$ in GARFIELD-AF; and across states within the United States, from 34\% to 0\% in ORBIT-AF II [16]. The differences between European, American, and global registries in the use of OACs can to some extent be connected with the differences in the researched populations. Europe's higher OAC use could result from more frequent NOAC use. This, in turn, may be linked to an explicit class I recommendation for the application of NOACs instead of VKAs included in ESC guidelines. Temporal trends in OAC prescription were observed. In the present study including Polish AF patients with a high stroke risk hospitalized in 2018, the percentage of patients treated with OACs was very high, and in another study also involving Polish AF patients but in the years 2004-2012, the percentage of patients treated with OACs was lower, at 65\% [17].

This study showed promising trends in oral anticoagulation for AF according to NOAC prescription. Major and randomized clinical trials have demonstrated the noninferiority or superiority of each NOAC compared to VKAs for stroke prevention [18-20]. A meta-analysis of these trials demonstrated very favorable risk-benefit profiles for NOACs versus VKAs [21]. The introduction of NOACs in 2010 changed the landscape of stroke prevention in AF. In our study, most patients with a high risk of stroke were treated with NOACs. These results were in line with the results from other studies. In GARFIELD-AF, the percentage of prescribed NOACs increased from $34 \%$ to $62 \%$ in 3 years [22]. The EORP-AF General Long-Term General Registry, in comparison to EORP-AF Pilot, indicated that over the course of four years there was a rise of NOAC prescription from less than $10 \%$ to about $35 \%$ of patients $[21,23]$. Observing temporal trends in anticoagulant treatment, it is possible to forecast a further increase of the percentage of patients with AF who will receive NOACs as a preventive treatment against thromboembolic complications. Therefore, NOACs, which have a better safety profile than VKAs, have become the agents of choice for patients who have not previously received antithrombotic or APT treatment.

Our observations indicate that clinicians are can identify the patients most appropriate for OAC treatment, and therefore administer this treatment to the most suitable candidates. However, among patients with high bleeding risk, the percentage of individuals for which OAC use was recommended was significantly lower. Indeed, in the present study, previous intracranial or gastrointestinal bleeding and specific risk bleeding factors such as cancer, anemia, and hospitalization due to acute coronary syndrome were connected with a lack of OAC prescription. History of intracranial bleeding was the strongest predictor of OAC non-prescription. Similarly, Lee et al. [8] showed that a history of intracranial hemorrhage was associated with OAC underuse. The decision to include OACs after past intracranial bleeding is not easy. The pivotal clinical trials of all four NOACs excluded patients with a prior history of intracranial bleeding. In the analysis of patients after intracranial bleeding who started to receive OACs, it was shown that NOACs were associated with a significantly lower risk of intracranial bleeding compared to warfarin [24]. In the present study, gastrointestinal tract bleeding was also an important factor connected to OAC underuse. As in the study of Hess et al. [25], OACs were recommended less frequently in the group of patients with a high risk of thromboembolic complications who had a prior thromboembolic complication. Another factor connected with the restriction of OAC in patients indicated to obtain such a treatment was hospitalization due to acute coronary 
syndrome, and the associated necessity to use antiplatelet treatment. It appears that in clinical practice, adjusting the doses of NOACs or VKAs based on a clinical risk-benefit balance can result in problems when administering OACs and antiplatelet pharmaceuticals simultaneously. It is essential to observe that although the risk factors of bleeding are often included in composite bleeding risk scores such as the HAS-BLED score, current guidelines do not suggest withholding OACs due to a high predicted bleeding risk. Altogether, our findings underline persistent concern about bleeding complications in patients treated with OACs and emphasize the necessity for a better understanding of optimal stroke prevention strategies in AF patients with high stroke and bleeding risks.

\section{Study Strengths and Limitations}

The present study includes a unique description of clinical data from Polish AF populations rather than data from selected or registered patients from trials. Our findings show the real-world clinical practice pattern of antithrombotic strategy in AF patients. Several limitations of our study must be emphasized, however. Firstly, due to the lack of long-term patient observation, it was not possible to assess long-term prognosis in AF patients treated with an individual antithrombotic strategy. Secondly, there were hospitalized AF patients examined where only some of them had a first-time diagnosed AF, and only some of them started an anticoagulant treatment. Therefore, despite the registry referring to hospitalized patients, the anticoagulant therapy in most of them began in ambulatory conditions prior to hospital admission. Patients hospitalized to undergo AF ablation were not included in the registry for two reasons: first of all, catheter ablation is not performed in all centers; secondly, it was recognized that a clinical profile of patients undergoing ablation due to AF is different from most AF patients in that they are younger and do not have concomitant diseases.

\section{Conclusions}

In the largest dedicated registry of Polish hospitalized patients with AF, the majority of patients with high stroke risk were treated with OACs. Factors associated with the absence of OACs were correlated with elevated bleeding risk, and previous bleeding was among the most important factors.

Supplementary Materials: The following are available online at https:/ /www.mdpi.com/article/10 $.3390 /$ jcm10194611/s1, Table S1: Factors associated with the selection of OACs over no OACs for stroke prevention in AF patients: univariable logistic regression models.

Author Contributions: Conceptualization, A.S. (Anna Szpotowicz), I.G., O.J., B.U.-Ż., A.K.-C. and B.W.-K.; methodology, A.S. (Anna Szpotowicz), I.G., B.U.-Ż., A.K.-C., A.T.-K., M.K. and B.W.-K.; software, J.B. (Janusz Bednarski), M.W. (Marcin Wełnicki); validation, A.S. (Anna Szpotowicz), I.G., B.U.-Ż., M.W. (Maciej Wójcik), R.B. and B.W.-K.; formal analysis, A.S. (Anna Szpotowicz), I.G., O.J., M.W. (Maciej Wójcik), M.B. and A.M.; investigation, A.S. (Anna Szpotowicz), I.G., O.J., B.U.-Ż., M.M., A.K.-C., M.B., M.G., T.T., R.R.-S., J.B. (Jacek Bil), and M.W. (Michał Wojewódzki); resources, A.S. (Anna Szpotowicz), I.G. and B.W.-K.; data curation, A.S. (Anna Szpotowicz), O.J., R.B., T.T., E.B.-O., A.S. (Anna Szyszkowska), M.W. (Michał Wojewódzki), and M.W. (Marcin Wełnicki); writingoriginal draft preparation, A.S. (Anna Szpotowicz) and I.G.; writing-review and editing, A.K.-C., J.B. (Janusz Bednarski), A.T.-K., A.M. and B.W.-K.; visualization, A.S. (Anna Szpotowicz), M.K. and M.M.; supervision, B.W.-K. All authors have read and agreed to the published version of the manuscript.

Funding: This research received no external funding.

Institutional Review Board Statement: The study was conducted according to the guidelines of the Declaration of Helsinki, and approved by The Ethics Committee of the Świętokrzyska Medical Chamber in Kielce (104/2018).

Informed Consent Statement: The Ethics Committee waived the requirement for informed conset from the patients.

Data Availability Statement: Data are contained within the article. 
Acknowledgments: The POL-AF registry was initiated on the Scientific Platform of the "Club 30" of the Polish Cardiac Society. Investigators other than those listed as authors include Anna Michalska-Foryszewska (Kielce) and Paweł Krzesiński (Warszawa).

Conflicts of Interest: A.S. (Anna Szpotowicz), O.J., B.U.-Ż., M.M., M.W. (Michał Wojewódzki), R.B., M.B., M.G., T.T., R.R.-S., J.B. (Jacek Bil), M.W. (Michał Wojewódzki), E.B.-O., A.S. (Anna Szyszkowska), M.W. (Marcin Wełnicki), M.M. and M.K.: none. I.G.: speaker for Boehringer-Ingelheim and Bayer. A.K.-C.: speaker for Bayer. J.B. (Janusz Bednarski): speaker for Boehringer-Ingelheim, Bayer, and Pfizer. A.T.-K.: research grant from Boehringer-Ingelheim, consultant for Boehringer-Ingelheim and Bayer, and speaker for Boehringer-Ingelheim. B.W.-K.: speaker for Boehringer-Ingelheim, Bayer, and Pfizer.

\section{References}

1. Wolf, P.A.; Abbott, R.D.; Kannel, W.B. Atrial fibrillation as an independent risk factor for stroke: The Framingham Study. Stroke 1991, 22, 983-988. [CrossRef] [PubMed]

2. Freedman, J.F.; Gersh, B.J. Atrial fibrillation and stroke prevention in aging patients. Circulation 2014, 130, 129-131. [CrossRef] [PubMed]

3. Piccini, J.P.; Stevens, S.R.; Chang, Y.; Singer, D.E.; Lokhnygina, Y.; Go, A.S.; Patel, M.R.; Mahaffey, K.W.; Halperin, J.L.; Breithardt, G.; et al. Renal dysfunction as a predictor of stroke and systemic embolism in patients with nonvalvular atrial fibrillation: Validation of the R(2)CHADS(2) index in the ROCKET AF (Rivaroxaban Once-daily, oral, direct factor Xa inhibition Compared with vitamin $\mathrm{K}$ antagonism for prevention of stroke and Embolism Trial in Atrial Fibrillation) and ATRIA (AnTicoagulation and Risk factors In Atrial fibrillation) study cohorts. Circulation 2013, 127, 224-232. [CrossRef] [PubMed]

4. Gage, B.F.; Waterman, A.D.; Shannon, W.; Boechler, M.; Rich, M.W.; Radford, M.J. Validation of clinical classification schemes for predicting stroke: Results from the National Registry of Atrial Fibrillation. JAMA 2001, 285, 2864-2870. [CrossRef] [PubMed]

5. Lip, G.Y.; Nieuwlaat, R.; Pisters, R.; Lane, D.A.; Crijns, H.J. Refining clinical risk stratification for predicting stroke and thromboembolism in atrial fibrillation using a novel risk factor-based approach: The euro heart survey on atrial fibrillation. Chest 2010, 137, 263-272. [CrossRef] [PubMed]

6. Steinberg, B.A.; Gao, H.; Shrader, P.; Pieper, K.; Thomas, L.; Camm, A.J.; Ezekowitz, M.D.; Fonarow, G.C.; Gersh, B.J.; Goldhaber, S.; et al. International trends in clinical characteristics and oral anticoagulation treatment for patients with atrial fibrillation: Results from the GARFIELD-AF, ORBIT-AF I and ORBIT-AF II registries. Am. Heart. J. 2017, 194, 132-140. [CrossRef] [PubMed]

7. Huiart, L.; Ferdynus, C.; Renoux, C.; Beaugrand, A.; Lafarge, S.; Bruneau, L.; Suissa, S.; Maillard, O.; Ranouil, X. Trends in initiation of direct oral anticoagulant therapies for atrial fibrillation in a national population-based cross-sectional study in the French health insurance databases. BMJ Open 2018, 30, e018180. [CrossRef]

8. $\quad$ Lee, S.R.; Choi, E.K.; Lee, S.Y.; Lee, E.; Han, K.D.; Cha, M.J.; Kwon, W.Y.; Shin, S.D.; Oh, S.; Lip, G. Temporal Trends of Emergency Department Visits of Patients with Atrial Fibrillation: A Nationwide Population-Based Study. J. Clin. Med. 2020, 9, 1485. [CrossRef]

9. Hindricks, G.; Potpara, T.; Dagres, N.; Arbelo, E.; Bax, J.J.; Blomström-Lundqvist, C.; Boriani, G.; Castella, M.; Dan, G.A.; Dilaveris, P.E.; et al. 2020 ESC Guidelines for the diagnosis and management of atrial fibrillation developed in collaboration with the European Association of Cardio-Thoracic Surgery (EACTS). Eur. Heart. J. 2020, 42, 373-498. [CrossRef]

10. Pisters, R.; Lane, D.A.; Nieuwlaat, R.; de Vos, C.B.; Crijns, H.J.; Lip, G.Y.H. A novel user-friendly score (HAS-BLED) to assess 1-year risk of major bleeding in patients with atrial fibrillation: The Euro Heart Survey. Chest 2010, 138, 1093-1100. [CrossRef] [PubMed]

11. Kirchhof, P.; Benussi, S.; Kotecha, D.; Ahlsson, A.; Atar, D.; Casadei, B.; Castellá, M.; Diener, H.C.; Heidbuchel, H.; Hendriks, J.; et al. 2016 ESC Guidelines for the Management of Atrial Fibrillation Developed in Collaboration With EACTS. Europace 2016, 18, 1609-1678. [CrossRef]

12. Heidbuchel, H.; Verhamme, P.; Alings, M.; Antz, M.; Diener, H.C.; Hacke, W.; Oldgren, J.; Sinnaeve, P.; Camm, A.J.; Kirchhof, P.; et al. Updated European Heart Rhythm Association Practical Guide on the use of non-vitamin K antagonist anticoagulants in patients with non-valvular atrialfibrillation. Europace 2015, 17, 1467-1507. [CrossRef]

13. Heidbuchel, H.; Verhamme, P.; Alings, M.; Antz, M.; Hacke, W.; Oldgren, J.; Sinnaeve, P.; Camm, A.J.; Kirchhof, P. European Heart Rhythm Association Practical Guide on the use of new oral anticoagulants in patients with non-valvular atrial fibrillation. Europace 2013, 15, 625-651. [CrossRef]

14. Steffel, J.; Verhamme, P.; Potpara, T.S.; Albaladejo, P.; Antz, M.; Desteghe, L.; Haeusler, K.G.; Oldgren, J.; Reinecke, H.; RoldanSchilling, V.; et al. The 2018 European Heart Rhythm Association Practical Guide on the use of non-vitamin K antagonist oral anticoagulants in patients with atrial fibrillation: Executive summary. Europace 2018, 20, 1231-1242. [CrossRef]

15. Lubitz, S.A.; Khurshid, S.; Weng, L.C.; Doros, G.; Keach, J.W.; Gao, Q.; Gehi, A.K.; Hsu, J.C.; Reynolds, M.R.; Turakhia, M.P.; et al. Predictors of oral anticoagulant non-prescription in patients with atrial fibrillation and elevated stroke risk. Am. Heart J. 2018, 200, 24-31. [CrossRef] 
16. Gorczyca, I.; Wożakowska-Kapłon, B.; Starzyk, K.; Szpotowicz, A.; Stec, A. Evaluation of the recommended prevention of thrombosis in hospitalised patients with atrial fibrillation and high thromboembolism risk. Kardiol. Pol. 2018, 76, 625-632. [CrossRef]

17. Granger, C.; Alexander, J.; McMurray, J.; Lopes, R.D.; Hylek, E.M.; Hanna, M.; Al-Khalidi, H.R.; Ansell, J.; Atar, D.; Avezum, A.; et al. Apixaban versus warfarin in patients with atrial fibrillation. N. Engl. J. Med. 2011, 365, 981-992. [CrossRef] [PubMed]

18. Connolly, S.; Ezekowitz, M.; Yusuf, S.; Eikelboom, J.; Oldgren, J.; Parekh, A.; Pogue, J.; Reilly, P.A.; Themeles, E.; Varrone, J.; et al. Dabigatran versus warfarin in patients with atrial fibrillation. N. Engl. J. Med. 2009, 361, 1139-1151. [CrossRef] [PubMed]

19. Patel, M.; Mahaffey, K.; Garg, J.; Pan, G.; Singer, D.E.; Hacke, W.; Breithardt, G.; Halperin, J.L.; Hankey, G.J.; Piccini, J.P.; et al. Rivaroxaban versus warfarin in nonvalvular atrial fibrillation. N. Engl. J. Med. 2011, 365, 883-891. [CrossRef] [PubMed]

20. Ruff, C.T.; Giugliano, R.P.; Braunwald, E.; Hoffman, E.B.; Deenadayalu, N.; Ezekowitz, M.D.; Camm, A.J.; Weitz, J.I.; Lewis, B.S.; Parkhomenko, A.; et al. Comparison of the efficacy and safety of new oral anticoagulants with warfarin in patients with atrial fibrillation: A meta-analysis of randomised trials. Lancet 2014, 383, 955-962. [CrossRef]

21. Boriani, G.; Proietti, M.; Laroche, C.; Fauchier, L.; Marin, F.; Nabauer, M.; Potpara, T.; Dan, G.A.; Kalarus, Z.; Diemberger, I.; et al. Contemporary stroke prevention strategies in 11096 European patients with atrial fibrillation: A report from the EURObservational Research Programme on Atrial Fibrillation (EORP-AF) Long-Term General Registry. Europace 2018, 20, 747-757. [CrossRef]

22. Bassand, J.P.; Accetta, G.; Al Mahmeed, W.; Corbalan, R.; Eikelboom, J.; Fitzmaurice, D.A.; Fox, K.; Gao, H.; Goldhaber, S.Z.; Goto, S.; et al. Risk factors for death, stroke, and bleeding in 28,628 patients from the GARFIELD-AF registry: Rationale for comprehensive management of atrial fibrillation. PLoS ONE 2018, 13, e0191592. [CrossRef] [PubMed]

23. Lip, G.Y.; Laroche, C.; Dan, G.A.; Santini, M.; Kalarus, Z.; Rasmussen, L.H.; Oliveira, M.M.; Mairesse, G.; Crijns, H.J.; Simantirakis, E.; et al. A prospective survey in European Society of Cardiology member countries of atrial fibrillation management: Baseline results of EURObservational Research Programme Atrial Fibrillation (EORP-AF) Pilot General Registry. Europace 2014, 16, 308-319. [CrossRef] [PubMed]

24. Lee, S.R.; Choi, E.K.; Kwon, S.; Jung, J.H.; Han, K.D.; Cha, M.J.; Oh, S.; Lip, G. Oral Anticoagulation in Asian Patients with Atrial Fibrillation and a History of Intracranial Hemorrhage. Stroke 2020, 51, 416-423. [CrossRef] [PubMed]

25. Hess, P.L.; Kim, S.; Fonarow, G.C.; Thomas, L.; Singer, D.E.; Freeman, J.V.; Gersh, B.J.; Ansell, J.; Kowey, P.R.; Mahaffey, K.W.; et al. Absence of Oral Anticoagulation and Subsequent Outcomes Among Outpatients with Atrial Fibrillation. Am. J. Med. 2017, 130, 449-456. [CrossRef] [PubMed] 